\title{
Effects of curing on emulsion cold mix asphalts and their extracted binder
}

\author{
Amélie Thiriet ${ }^{1}$, Vincent Gaudefroy ${ }^{1 *}$, Emmanuel Chailleux $^{1}$, Jean-Michel Piau' ${ }^{1}$, Frédéric Delfosse ${ }^{2}$ and \\ Christine Leroy $^{2}$
}

\begin{abstract}
This paper focuses on the physicochemical changes that happen in cold mix asphalts during curing, and more specifically, while and after transitioning to different simulated seasons. Several tests were carried out in order to better grasp the influence of the weather (temperature and humidity) on the curing of such materials. The mechanical behaviour of the mix was assessed using oedometer tests. The physicochemical evolutions of extracted binders, such as oxidation and rheology, were evaluated. The results show stiffening of the mix and ageing of the binder linked to a higher temperature and a lower humidity. A low temperature and high moisture seem to slow down these evolutions. However the binder behaviour does not explain the whole mix behaviour as the kinetics between them are not always similar. Thus other mechanisms are yet to be found and taken into account to fully understand cold mix asphalts behaviour.
\end{abstract}

Keywords: Curing, Emulsion cold mix asphalt, Binder, Oedometer test, Rheology

\section{Introduction}

Cold mix asphalts are a composite material obtained by mixing a bitumen emulsion (bitumen droplets dispersed in an aqueous phase) with aggregates. At the final stage aggregates are linked together by the organic binder after the emulsion break. The material stiffens with time while water drains off in a phase called curing.

These materials are mostly used for pavement (road repair and structure of low traffic roads). This type of material could be an answer to the ecological issue. Contrary to hot mix asphalts which are manufactured at $160{ }^{\circ} \mathrm{C}$, cold mix asphalts process requires emulsified bitumen and cold and wet rocks, saving energy to heat it up and preventing fumes generation. Nevertheless, cold mix mechanical behaviour during curing is relatively unknown and final performances are difficult to predict. The presence of water and its removal are one of the main differences compared to hot mix asphalt and they

\footnotetext{
* Correspondence: vincent.gaudefroy@univ-eiffel.fr

'Université Gustave Eiffel/IFSTTAR (French institute of science and technology for transport, development and network), Nantes, France Full list of author information is available at the end of the article
}

greatly influence the evolution of such a material. Furthermore it is known that the curing of emulsion cold mix asphalt is highly dependent on external parameters such as the climatic conditions $[1,2]$ or the composition [3]. Apart from increase of stiffness, the curing also influences other aspects of the material as stiffening and oxidation (ageing) of the binder, as is has already been studied for hot and cold bituminous mixes [4-7].

To improve knowledge on emulsion cold mix asphalts and thus facilitate their use, an assessment of their behaviour during curing and a better understanding of their curing mechanisms are needed. The ambition of this paper is to give an idea of the different aspects of curing on emulsion cold mix asphalts and understand the influence of the implementation season. These issues were assessed by comparing the mix mechanical evolution with the physicochemical characteristics of the binder with time. This comparison will give information about the different physical and chemical phenomena involved in the curing process. More precisely, cold mix asphalt samples were tested by oedometer test all along curing and their binder was extracted and studied at 
different curing times, with IR, rheology and calorimetry. The rheological evolution of the binder allows a direct understanding of the influence of the binder on the whole mix. A change in glass transition measured with calorimetry could account for binder weakening during curing. The oxidation (quantified with IR) and increase of modulus of the binder would indicate its ageing.

\section{Materials and methods}

\section{Materials}

The emulsion cold mix asphalt samples were made with a 70/100 bitumen emulsion at $65 / 35$ bitumen-water ratio and virgin aggregates. The residual binder content was $4.55 \%$ and the total water content $6.50 \%$. The material was compacted at $10 \%$ void content (including voids filled with air and voids filled with water) in cylindrical molds (120 mm diameter, $60 \mathrm{~mm}$ height).

\section{Conditioning procedures}

All the samples were cured in a BIA CL1-30 climatic chamber at the following parameters:

- Nine samples were cured at $35^{\circ} \mathrm{C}$ and $20 \% \mathrm{RH}$ during two months followed by $10{ }^{\circ} \mathrm{C}$ and $80 \% \mathrm{RH}$ for two months. This group is called group A.

- Seven samples went through two months at $10{ }^{\circ} \mathrm{C}$ and $80 \% \mathrm{RH}$ and then two months at $35{ }^{\circ} \mathrm{C}$ and $20 \% \mathrm{RH}$. This group is called group B.

The $35{ }^{\circ} \mathrm{C}$ and $20 \% \mathrm{RH}$ curing parameters have been numerously applied in the literature $[6-8,10]$ in particular when used for 15 days to simulate two or three summers of curing on-site. In this study, they are used to simulate a warm season. The $10{ }^{\circ} \mathrm{C}-80 \% \mathrm{RH}$ parameters are chosen to simulate a cold season.

The samples were then removed from the chamber at specific times and separated into two testing groups: a batch of samples was tested with oedometric testing (non-destructive testing) while the binder was extracted from samples of the other batch all along the curing process (destructive testing).

\section{Test procedure}

\section{Oedometric tests}

The mechanical behaviour of the samples was evaluated with a Schenck Prüfrahmen Typ press to measure the oedometric moduli at different curing times according to Lambert's method [9]. This technique uses cyclic compression of a specimen that is set in a cylindrical mold (120 mm diameter) to calculate the stiffness of a non-cohesive material. As the sample is contained in the mold, only vertical displacements occur. The last cycle of each sequence (one sequence for one frequency tested), considered as stabilised, is used to determine the modulus and phase angle. The modulus is calculated by dividing the stress amplitude with the strain amplitude. The phase angle is obtained with the subtraction between the arguments of the stress and strain signals.

During a test, five frequencies $(0.1,1,3,6$ and $10 \mathrm{~Hz})$ are applied, along with three loading forces $(2.8,5.1$ and $9.5 \mathrm{kN}) .10$ cycles are used for $0.1 \mathrm{~Hz}, 50$ for $1 \mathrm{~Hz}, 75$ for $3 \mathrm{~Hz}, 75$ for $6 \mathrm{~Hz}$ and 100 for $10 \mathrm{~Hz}$. All of these parameters are tested at three test temperatures: 15, 25 and $35{ }^{\circ} \mathrm{C}$. As the samples under loading are not temperature controlled, they are placed in a climatic chamber at the tested temperature at least $2 \mathrm{~h}$ before test sequence. This procedure is repeated for each test temperature.

To simplify results presentation, only the data from the tests at $15{ }^{\circ} \mathrm{C}, 10 \mathrm{~Hz}$ and $9.5 \mathrm{kN}$ are shown.

Along with the oedometer tests, these samples were regularly weighed by subtraction between the measured mass and the mold mass, and their heights were measured using a depth gauge allowing them to remain in their molds. Assuming that when the weight was minimal the samples were dry, the water content versus time was deduced with the Eq. $100 \% \times\left(\mathrm{m}_{\text {sample }}(\mathrm{t})-\mathrm{m}_{\text {sample }}(-\right.$ $\min )) /\left(\mathrm{m}_{\text {sample }}(\mathrm{t}=0)-\mathrm{m}_{\text {sample }}(\mathrm{min})\right)$.

Three samples were used for group A and two for group B.

\section{Binder extraction procedure}

The binder was extracted from the rest of the samples using an asphalt analyser Asphalt Analysator and tetrachloroethylene as solvant. Prior to the extraction process, those samples were lyophilized with an Alpha 1-2 plate LDplus (Bioblock-Christ) freeze dryer in order to remove water, without using drying and heating steps to prevent further curing and oxidation. The collected binder was then centrifuged and distilled to remove the sand from the mix and the tetrachloroethylene from the extraction. After this procedure, the rheological behaviour, the glass transition and the oxidation of the extracted binders were studied.

\section{Complex modulus measurement}

The rheology measurements were done using an Anton Paar MCR102 DSR. Two plate-plate sample holders were used: an $8 \mathrm{~mm}$ diameter one for a range of temperature from 20 to $-10{ }^{\circ} \mathrm{C}$ (5000 Pa imposed stress) and a $25 \mathrm{~mm}$ diameter one for a range from 20 to $80{ }^{\circ} \mathrm{C}$ (500 Pa imposed stress). The gap was $1 \mathrm{~mm}$. Both ranges of temperatures were tested between 0.1 and $100 \mathrm{~Hz}$.

\section{DSC}

Two different samples weighing between 15 and $20 \mathrm{mg}$ were tested in calorimetry for each extracted binder with a Mettler Toledo DSC3 DSC, the data was retrieved 
during an increase of temperature at $10{ }^{\circ} \mathrm{C} / \mathrm{min}$. The data given in the results section of this paper are the mean values between the two tests. The glass transition temperature was directly extracted from the thermograms using the inflection point between start and end of the transition. The crystallised fractions were deduced from the area between the end of the glass transition and a temperature of $95{ }^{\circ} \mathrm{C}$. This area was then divided by the melting enthalpy of crystallised fraction $\Delta \mathrm{H}_{\mathrm{m}}$ (equal to $200 \mathrm{~J} \cdot \mathrm{g}^{-1}$ ) to obtain the crystallised fractions content.

\section{FTIR}

Finally, the FTIR tests consisted in measuring the oxidation levels $\mathrm{SO}$ and $\mathrm{CO}$ of the binders by transmission on thin film, on five samples for each extracted binder. The device used was a Perkin Elmer Spectrum Two. The oxidation levels were deduced from the areas centred around $1700 \mathrm{~cm}^{-1}$ for the $\mathrm{CO}$ index, and around $1030 \mathrm{~cm}^{-1}$ for the SO index. Each of these areas was divided by the addition of the areas of ethylene (centred around $1460 \mathrm{~cm}^{-1}$ ) and methyl (centred around $1375 \mathrm{~cm}^{-1}$ ), that are known to not evolve with binder oxidation.

\section{Results}

\section{Evolution of the water content and samples geometry}

Figure 1 shows the water contents in groups A and B. The kinetics of water loss is higher for group A (Fig. 1.a): the samples are supposed dry after around 15 days, while samples from group B (Fig. 1.-b) are supposed dry after 70 days (beginning of the "summer " curing parameters). Specimens from group A incorporate a small amount of water during the cold period $\left(10{ }^{\circ} \mathrm{C}-\right.$ $80 \% \mathrm{RH})$ and specimens from group B experience a severe drying when going from cold to warm conditions.

For group A (Fig. 2), there is a good link between water content and height: specimens lose height (around $1 \mathrm{~mm}$ ) at the same time as water (during the $35{ }^{\circ} \mathrm{C}-$ $20 \%$ RH curing parameters, Fig. 3.-a) and seem to gain height and water during the cold curing parameters (not enough measurements were made on height to be sure about its gain during the cold conditions).

Group B (Fig. 3.-b) behaviour is slightly different: during the cold period (the first 60 days), the specimens lose water (Fig. 1.-b) but their height remains constant (around $60.3 \mathrm{~mm}$ ). Moreover, during the $35{ }^{\circ} \mathrm{C}-$ $20 \% \mathrm{RH}$ curing process, what was left of water in the samples is lost in about 7 days, while the shrinkage happens during more than a month (from about 71 to 108 curing days). Then, the height does not seem to change anymore. This could be explained by the rheological behaviour of the binder and the mix moisture during curing. The volume variations could mainly be influenced by the binder movements on the aggregate (probably by wetting/dewetting). At $10{ }^{\circ} \mathrm{C}$ and $80 \% \mathrm{RH}$ the binder is less soft (around $10^{7} \mathrm{~Pa}$ at $10{ }^{\circ} \mathrm{C}$ and $10 \mathrm{~Hz}$ ) and there is still a high amount of water in the samples. This could prevent the mix shrinkage. After transition from $10{ }^{\circ} \mathrm{C}$ to $80 \% \mathrm{RH}$ to $35{ }^{\circ} \mathrm{C}$ and $20 \% \mathrm{RH}$ conditions, the binder is softer (around $10^{6} \mathrm{~Pa}$ at $35{ }^{\circ} \mathrm{C}$ and $10 \mathrm{~Hz}$ ) than at $10{ }^{\circ} \mathrm{C}$ so a shrinkage would be easier. The time difference between total loss of water (around 7 days) and the mix shrinkage (more than a month) can simply be explained by the high viscosity of the material resulting in a height loss inertia after water departure.

The height variations are also correlated to the void geometry that would change during curing and influence the modulus of the material. As a matter of fact, the void percentage of every sample was measured at the end of curing and the void content with curing time was deduced from the variations of geometry of each sample (Fig. 4), with the hypothesis that no material had been lost during the whole curing and that the void content is proportional to the height. At the end of the 4 months of curing, group A lost between 0,13 and $0,24 \%$ voids and group B between 0,08 and $0,11 \%$, which would imply a stiffening of both groups.

\section{Rheological behaviour of the mixture}

The stiffness modulus of the samples was assessed with an oedometer device [9]. Usually, other types of mechanical tests (indirect tensile or two-point bending for example) are used for the characterisation of asphalt mixes as they are already very stiff at an early age. Asphalt cold mixes take time to cure and become more cohesive to be tested with these devices, they are very weak at young age. Therefore the oedometer test appears to be a suitable testing technique to measure their mechanical behaviour.

Figure 5 displays the mean evolutions of oedometric modulus versus time for the samples from groups $\mathrm{A}$ and B (3 samples for group A and 2 for group B).

The kinetics of stiffness evolution are very different from one another. Indeed group A evolves rapidly and its modulus reaches more than $3000 \mathrm{MPa}$ after 60 days, when the one from group $\mathrm{B}$ reaches a value of about $2300 \mathrm{MPa}$ for the same period. The second curing parameters applied result in different trends. The modulus of samples from group A remains constant while the modulus of group B increases. For both conditioning procedures, stiffness increases slowly during the cold period and more quickly during a warm period. Finally, the modulus values for both groups are similar at the end of the curing process, which shows that seasons 

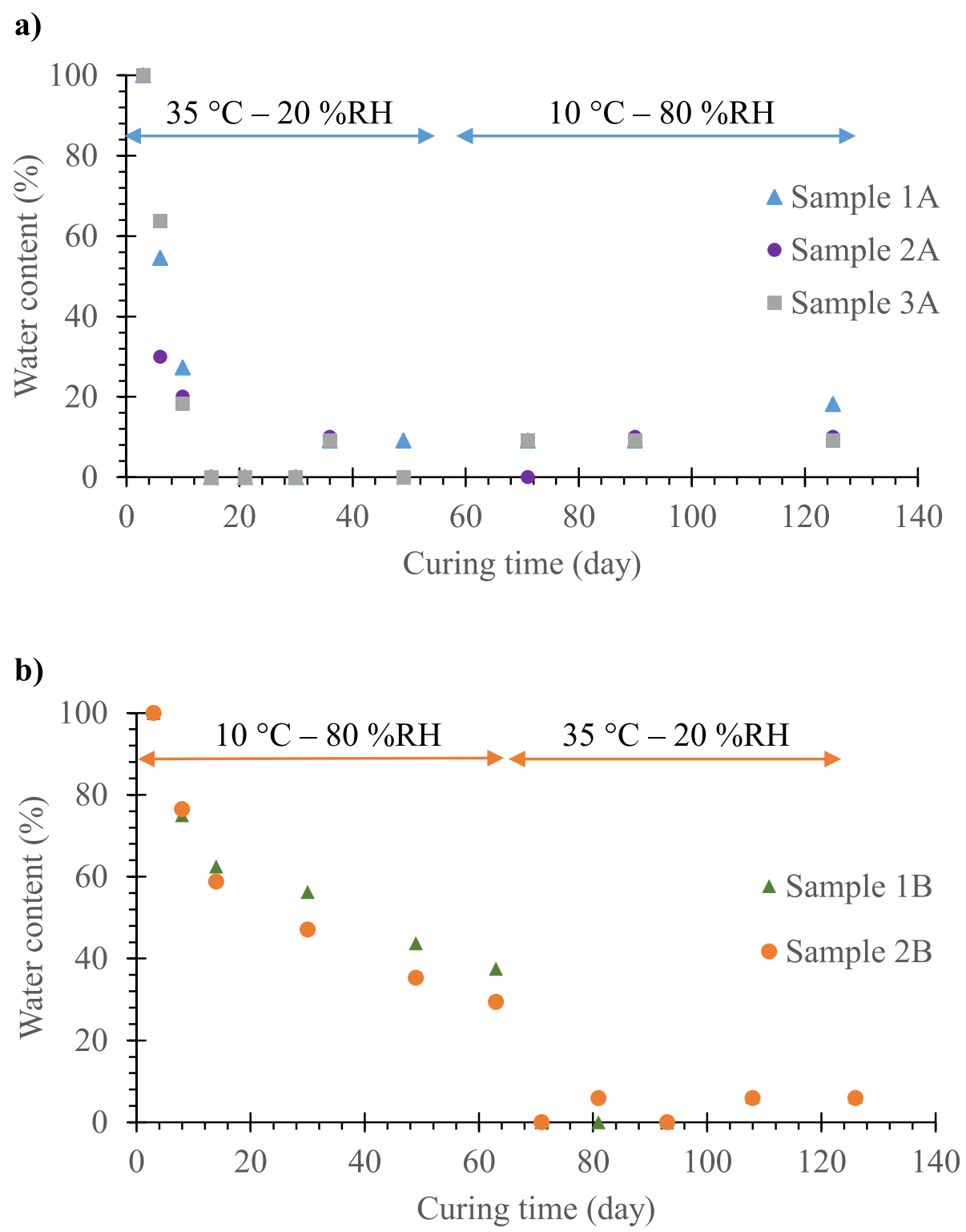

Fig. 1 Water content versus curing time in samples from group A (a) and B (b). Here we suppose that when the water content is minimal, the samples are dry.

sequence does not influence the curing of the material after about 130 days throughout the modulus.

Moreover, these evolutions can be compared to the water content in the samples (Fig. 6). Actually, in a general way, the modulus is lower when the water content is higher, and vice versa, when the water content is low, the modulus is higher. The same trends have already been examined for cold recycled bitumen emulsion mixtures containing cement [10] and for foamed asphalt cold recycled mixtures [11]. Besides the important stiffening at the beginning of curing for group A happens at the same time as the fast water loss of the samples (Fig. 1-a). In addition, the sudden increase of stiffness at the very beginning of the warm season for group $B$ (around 70 days) can be correlated to the sharp decrease of water content at the same time (Fig. 1-b). But the presence of water does not explain the whole behaviour of the material as it continues to evolve even when the water content is stable [12].

A change in the void content could also be correlated to the height variations and therefore influence the modulus: a decrease in void content would lead to a decrease in height thus an increase in modulus; whereas an increase in void content would result in an increase in height and a decrease in modulus. For example such as 


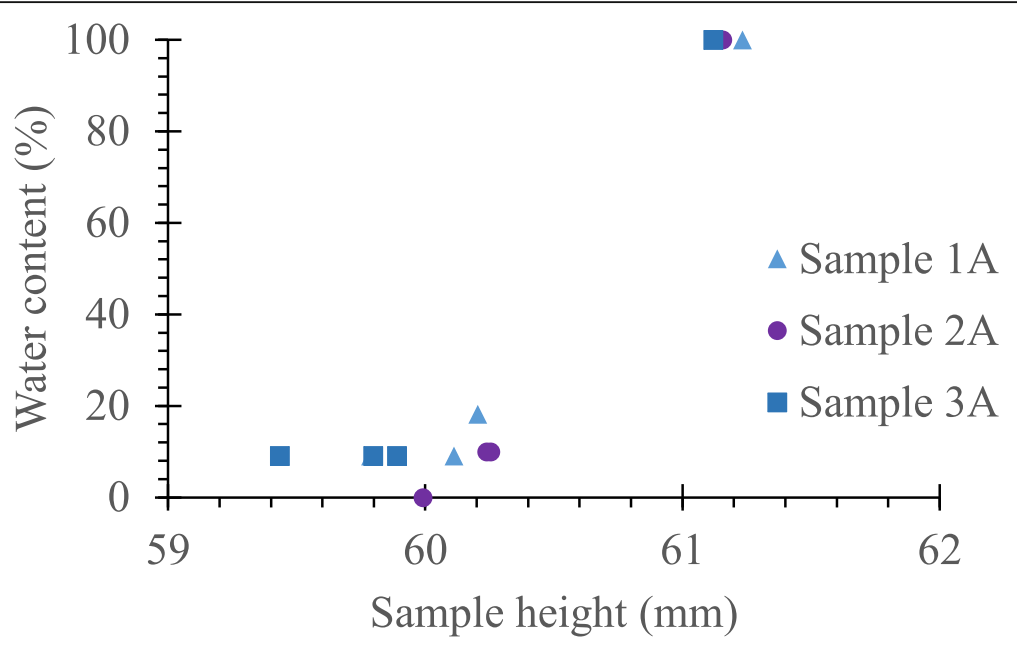

Fig. 2 Water content versus height of the samples from group A.
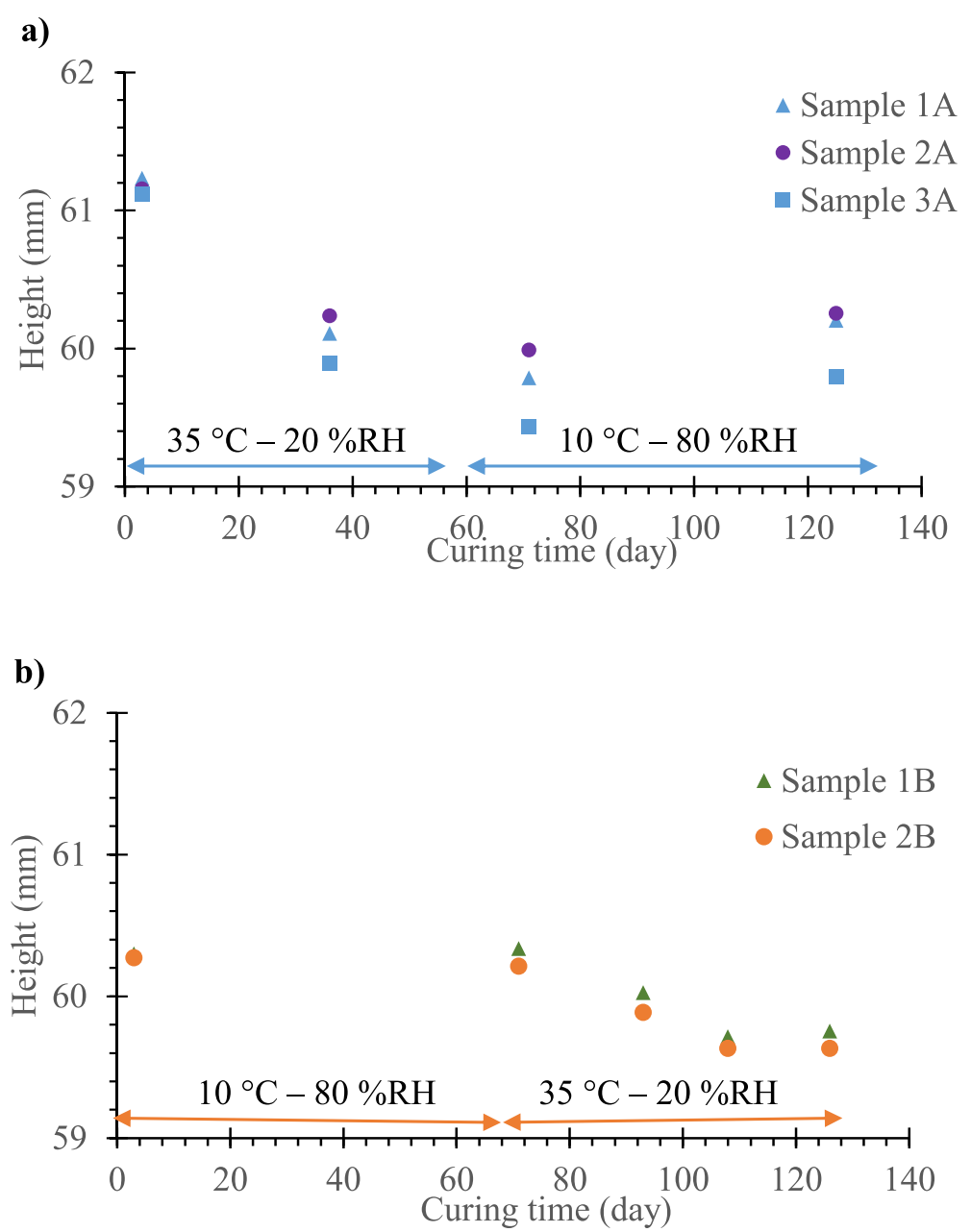

Fig. 3 Heights of samples from group A (a) and B (b). 


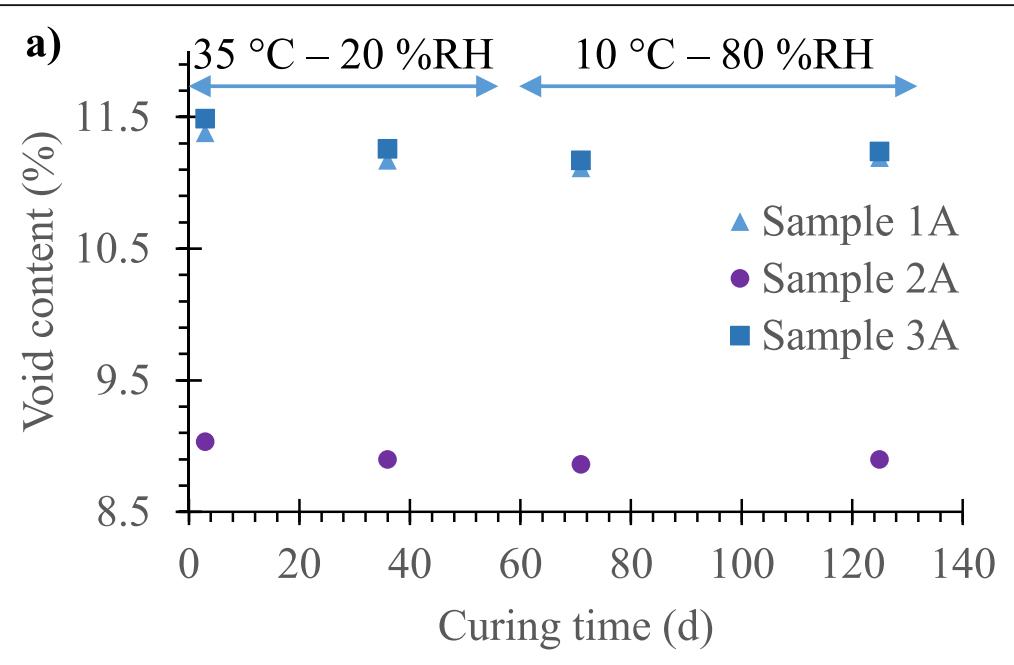

b)

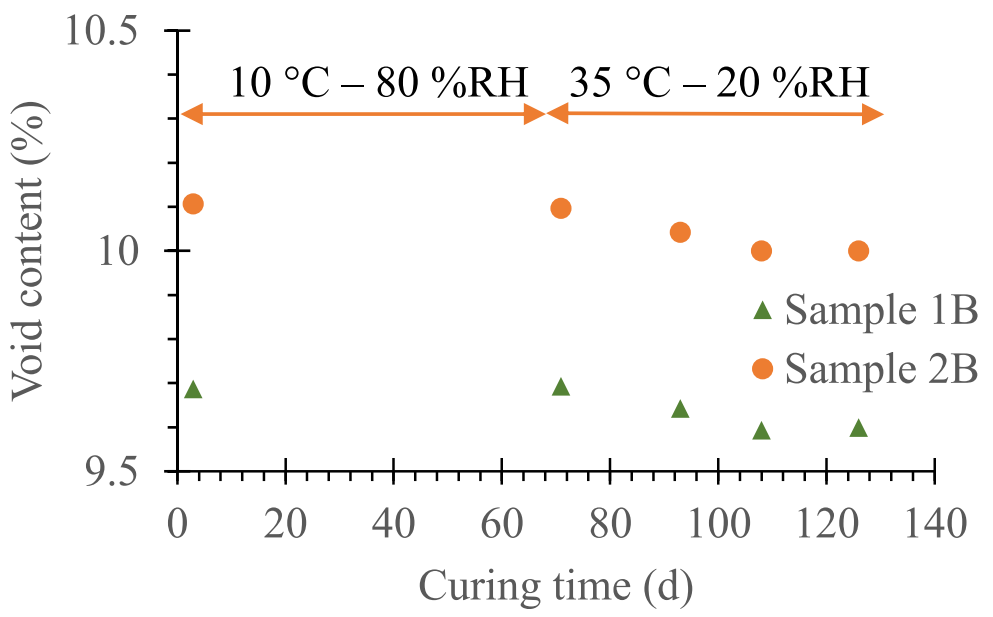

Fig. 4 Void content versus curing time of group A (a) and B (b).

seen in the $10{ }^{\circ} \mathrm{C}-80 \% \mathrm{RH}$ period of group A where the change in height would counteract the stiffening than happens normally over time.

Additionally, the void content results mentioned above could only explain part of the stiffening as the final and initial states of samples from both groups A and B are similar while the void content variations are higher for group A than for group B.

The phase angle represents the delay between the stress and strain signals. The initial and final states of the phase angle is similar for both groups. This means that, as for the oedometric modulus, the seasons sequence does not impact the final properties of the material, at our time scale. Two trends can be observed on Fig. 7. First of all, the phase angle decreases with time during a warm simulated season $\left(35{ }^{\circ} \mathrm{C}-20 \% \mathrm{RH}\right)$. A decrease of phase angle during curing has been shown on cold asphalt mixes with RAP and with and without cement [13]. For group A, it starts around $27^{\circ}$ and decreases to $23^{\circ}$ at the end of the two first months of curing. The trend of group $\mathrm{B}$ is trickier to assess as the angle also seems to decreases at $35{ }^{\circ} \mathrm{C}-20 \% \mathrm{RH}$ (3rd and 4th months) but each point remains in the standard deviation range of each other. Cold curing conditions $\left(10{ }^{\circ} \mathrm{C}-80 \% \mathrm{RH}\right)$ do not influence the phase angle. Indeed group A reaches $23^{\circ}$ and $22^{\circ}$ at the beginning and at the end of the simulated season respectively, while group B attains $27^{\circ}$ and $26^{\circ}$ respectively.

Moreover this data is in the same scale as can be found in the literature for cold mix asphalt [6].

\section{Extracted binder evolution}

As mentioned above, the comprehension of the physicochemical evolution of the binder could be extremely useful to grasp the whole mix behaviour and better understand the mechanisms at play during the curing process. The rheology, glass temperature and oxidation 


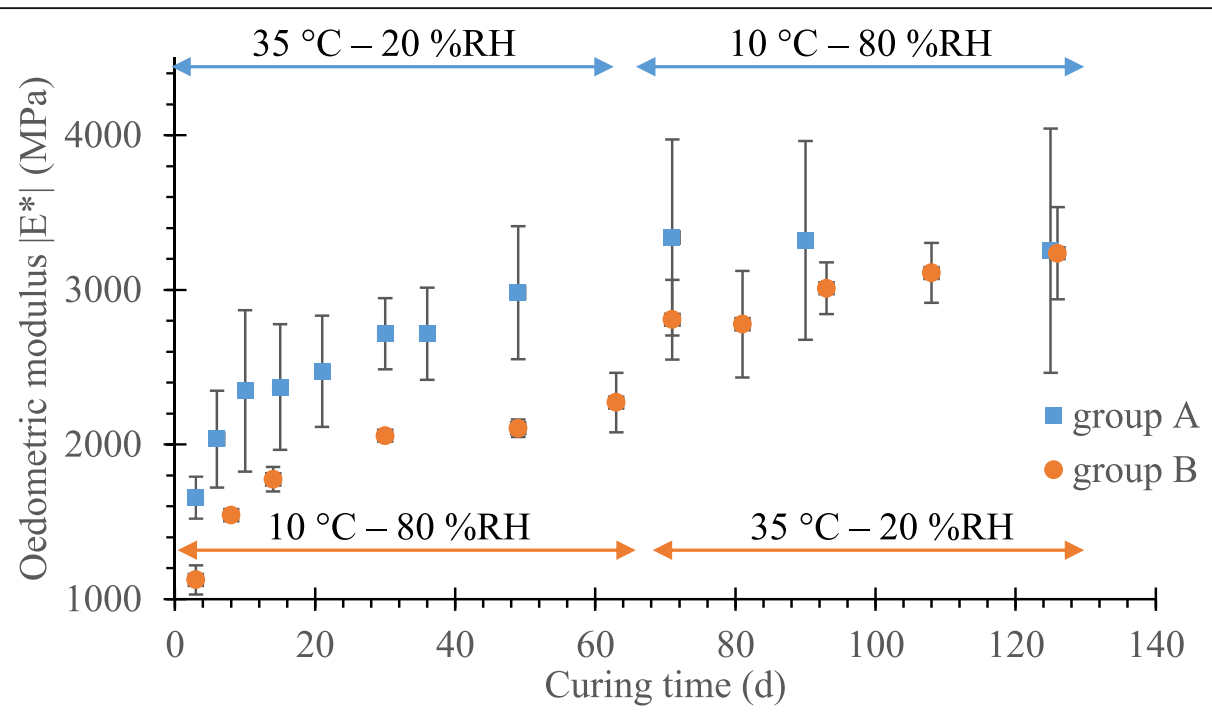

Fig. 5 Mean stiffness evolution of groups $\mathbf{A}$ and $\mathbf{B}$ with time, tested at $15^{\circ} \mathrm{C}, 10 \mathrm{~Hz}$ and $9.5 \mathrm{kN}$. The error bars represent the standard deviation on the three samples for group $\mathbf{A}$ and two for group $\mathbf{B}$.

bring information on the chemical variations and ageing of the binder.

\section{Rheological behaviour}

Shear modulus and phase angle Figure 8 highlights the differences in stiffening kinetics induced by the two different curing parameters. The literature shows that the shear modulus of a binder extracted from on-site cold mix asphalt increases with time [8], which is consistent with our results since the modulus of both groups has increased in four months. The standard deviation between the two furthest initial $(t=0)$ points is used to decide whether the following points are significantly different or not. For each mean value, this standard deviation is subtracted or added in order to get an upper and lower limit. If the modulus value of a point at curing time $t_{n}$ is included between the two limits of the previous point $t_{n-1}$ then the studied point $t_{n}$ is considered having a similar modulus value than the $t_{n-1}$ point.

Group A exhibits a fast increase of the complex shear modulus during the 60 first days at $35{ }^{\circ} \mathrm{C}-20 \% \mathrm{RH}$ and

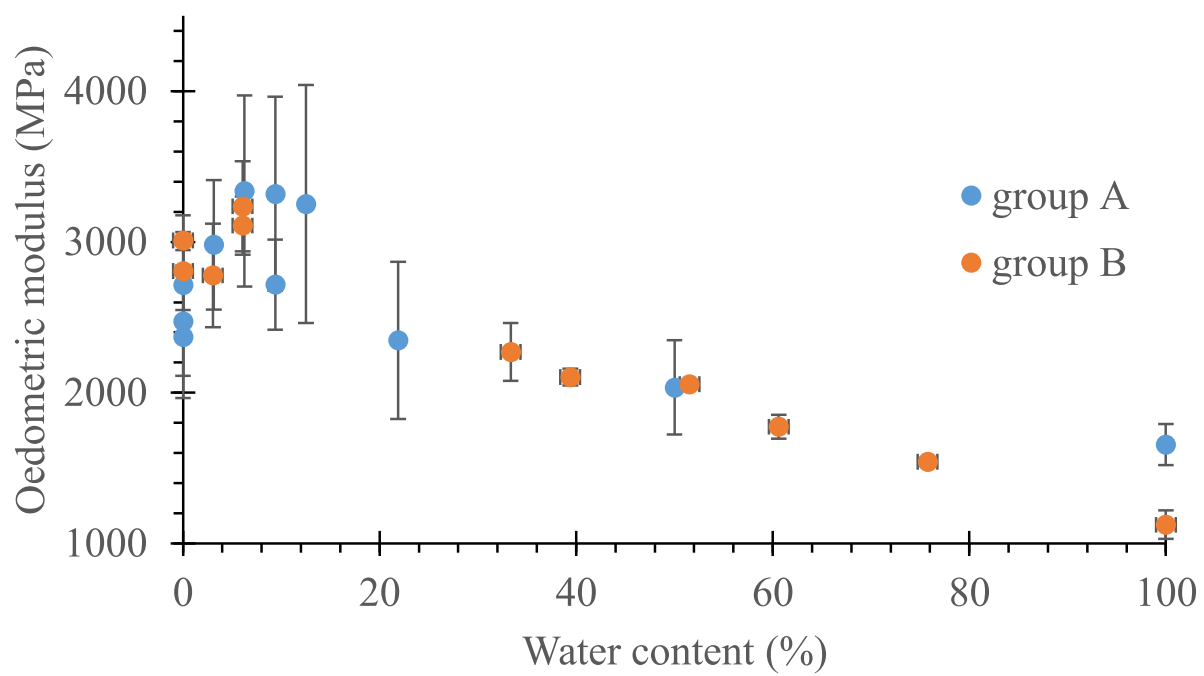

Fig. 6 Mean stiffness evolution of groups $A$ and $B$ versus mean water content, modulus tested at $15^{\circ} \mathrm{C}, 10 \mathrm{~Hz}$ and $9.5 \mathrm{kN}$. The error bars represent the standard deviation on the three samples for group $\mathbf{A}$ and two for group $\mathbf{B}$. Once again, we suppose that when the water content is minimal, the samples are dry. 


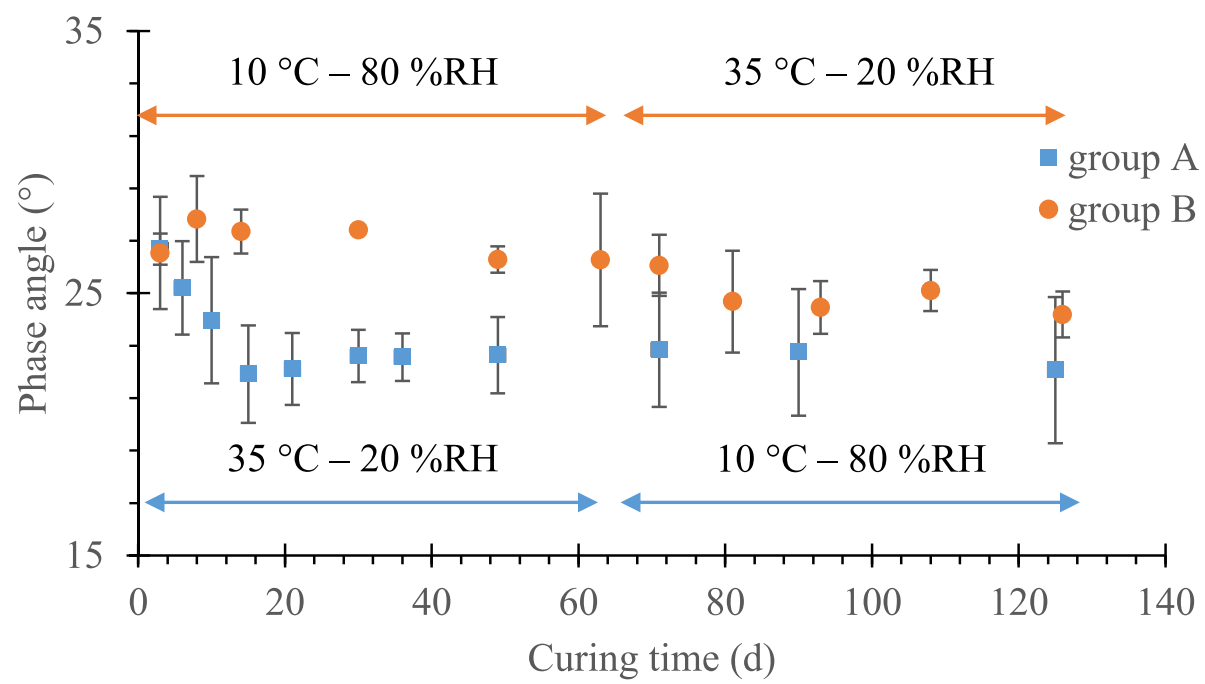

Fig. 7 Mean phase angle evolution of groups A and B with time, tested at $15{ }^{\circ} \mathrm{C}, 10 \mathrm{~Hz}$ and $9.5 \mathrm{kN}$. The error bars represent the standard deviation on the three samples for group $\mathbf{A}$ and two for group $\mathbf{B}$.

its stagnation during the next 60 days at $10{ }^{\circ} \mathrm{C}-$ $80 \% \mathrm{RH}$ as the modulus values at these curing parameters are considered similar.

As for group B, the shear modulus slightly decreases with time during curing at $10{ }^{\circ} \mathrm{C}$ and $80 \% \mathrm{RH}$ as the first and last points of these curing parameters are considered significantly different. During curing at $35{ }^{\circ} \mathrm{C}-$ $20 \% \mathrm{RH}$, the modulus then rises and reaches a value of about $7 \mathrm{MPa}$ after 90 days in a similar way than the one for group A at the same curing parameters. This evolution would undoubtedly lead to the same final state for both groups.

The significance of deviation between the phase angle points has been assessed the same way as previously on the shear modulus. The phase angle of the extracted binders of both groups does not highly evolve as it stays around $47-52^{\circ}$ for group $\mathrm{A}$ and between 52 and $59^{\circ}$ for group B (Fig. 9). Curing conditions at $35{ }^{\circ} \mathrm{C}$ and $20 \% \mathrm{RH}$ generally cause a decrease in the phase angle on both groups, regardless of their position in the four months of curing. The influence of the $10{ }^{\circ} \mathrm{C}-80 \% \mathrm{RH}$ curing conditions is trickier to examine: for group A (last two months of curing) there is no significant variation during those curing conditions. Phase angle values of group B (two first months of curing) slightly increase with time.

Thus the warm curing conditions $\left(35{ }^{\circ} \mathrm{C}-20 \% \mathrm{RH}\right)$ give the same response for the mix and the binder: a

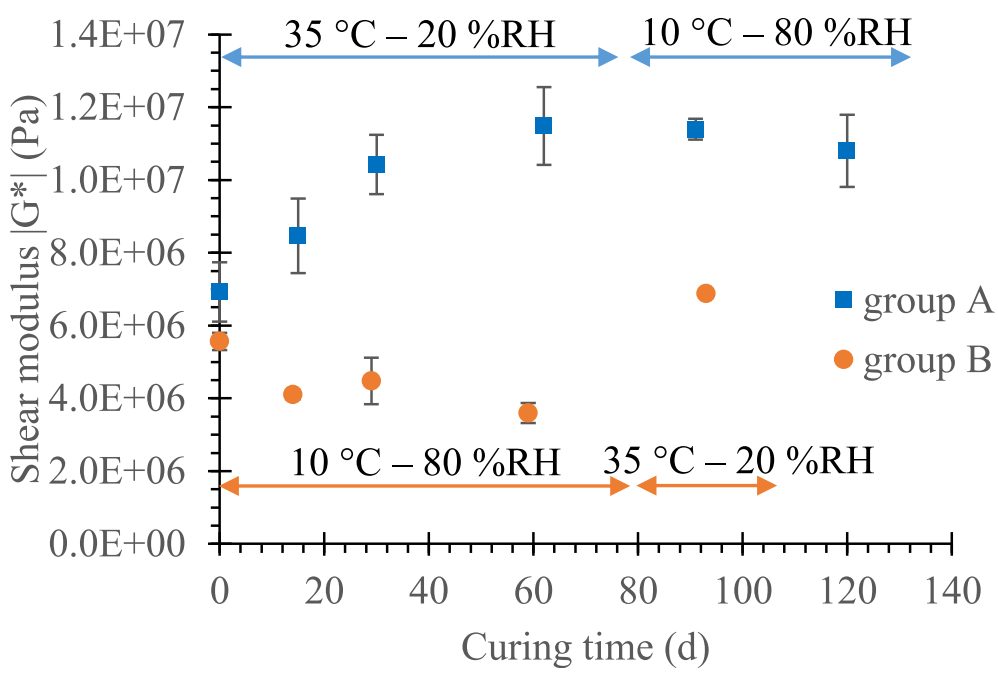

Fig. 8 Magnitude of $\mathrm{G}^{*}$ with time, tested at $20^{\circ} \mathrm{C}$ and $10 \mathrm{~Hz}$. The error bars represent the standard deviation on the two tests (for two ranges of temperature, as explained in the test procedure concerning the rheology) performed for each point on each sample. 


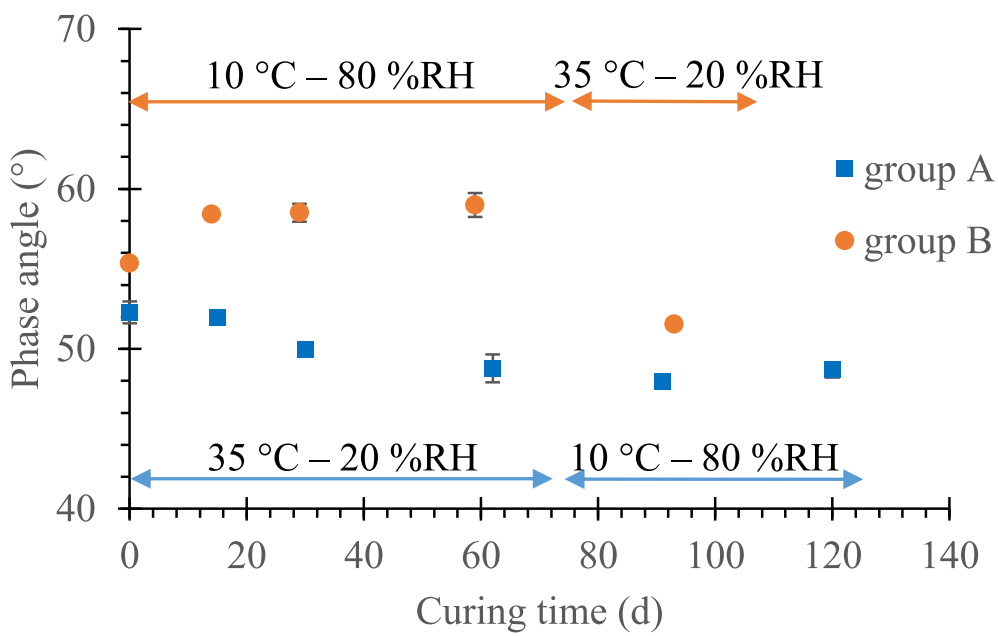

Fig. 9 Phase angle versus curing time, tested at $20{ }^{\circ} \mathrm{C}$ and $10 \mathrm{~Hz}$. The error bars represent the standard deviation on the two tests performed throughout the curing process on each sample.

decrease of phase angle. This was expected since the viscous behaviour of the mix is caused in majority, if only, by the binder behaviour. Besides, the phase angle of the binder is higher than of the mix. This is due to the presence of aggregates in the mix that give a more elastic behaviour to the mix (lower phase angle) than the binder.

Representation in the Black space The Black diagram of group A is illustrated in Fig. 10. Points 1, 2, 3 and 4 concerning binders which curing was stopped at 0,15 , 30 and 62 days respectively, during the warm period, show a stiffening and a decrease of phase angle with time. A stiffening is consistent with the literature and [14] showed that this progression is consistent with a physical hardening. The last two points (5 and 6, 91 and
120 days of curing, $10{ }^{\circ} \mathrm{C}-80 \% \mathrm{RH}$ ) indicate a stagnation of the binder.

Figure 11-a shows a light flattening between the curves at 0 and 93 days of curing (loss of phase angle and gain in modulus). This phenomenon has already been shown in the literature [4] and is consistent with an ageing of the material. This is not visible on group A, which shows that group B has started to age but not group A. This difference between the curves is still small, the studied time scales are definitely too short to see a stronger ageing.

The series of the first 4 points $(0,14,29$ and 59 curing days at $10{ }^{\circ} \mathrm{C}-80 \% \mathrm{RH}$ ) on Fig. 11 show an even more

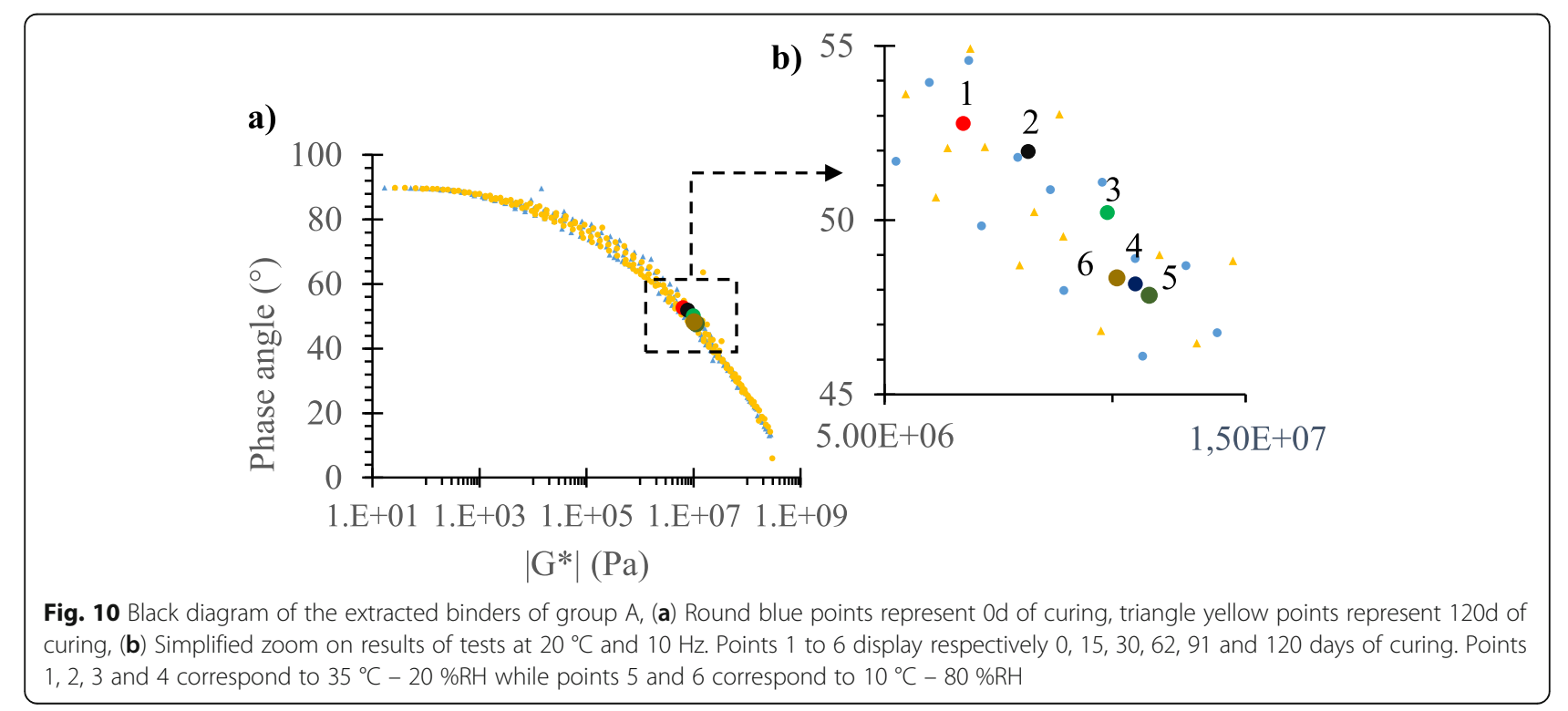




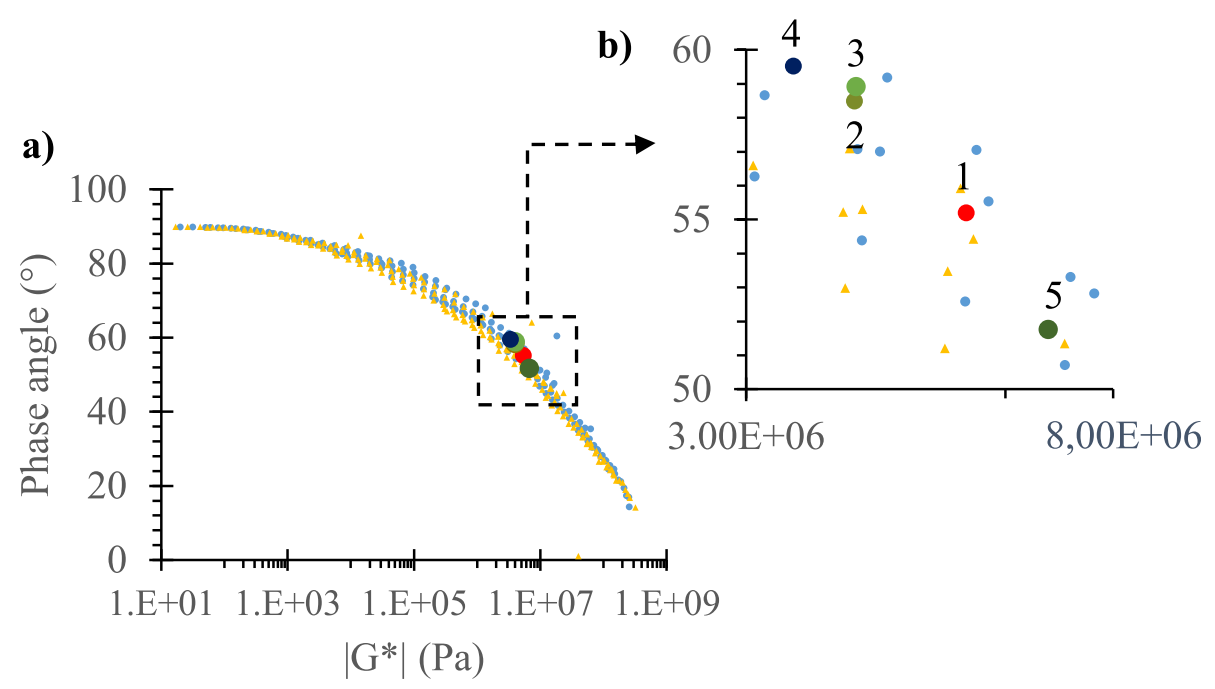

Fig. 11 Black diagram of the extracted binders of group B, (a) Round blue points represent 0d of curing, triangle yellow points represent $93 \mathrm{~d}$ of curing, (b) Simplified zoom on results of tests at $20^{\circ} \mathrm{C}$ and $10 \mathrm{~Hz}$. The smaller blue points represent the extracted binder at $\mathrm{t}=0$ and every tested temperatures and frequencies. Points 1 to 5 display respectively $0,14,29,59$ and 93 days of curing. Points $1,2,3$ and 4 correspond to $10^{\circ} \mathrm{C}-$ $80 \% \mathrm{RH}$ while point 5 corresponds to $35^{\circ} \mathrm{C}-20 \% \mathrm{RH}$.

significant trend to the one seen on Fig. 10 for the same simulated season: during the 2 months at $10{ }^{\circ} \mathrm{C}$ and $80 \% \mathrm{RH}$, group $\mathrm{B}$ has lost stiffness and gained phase angle where A has not. This trend for group B (a gain in phase angle in addition to a loss of modulus) has never been noticed in the literature, to the author's knowledge. This can be explained by the fact that the extracted binder of a cold mix cured in cold conditions $\left(10{ }^{\circ} \mathrm{C}-\right.$ $80 \% \mathrm{RH}$ for instance) has never, once again to the author's knowledge, been studied. This difference in kinetics between A and B during cold conditions may be related to their initial states : group $\mathrm{A}$ has already been through a warmer period which may have started physicochemical processes that B has not seen yet, which would explain the inertia of softening seen on Fig. 10 between points 4 and 5 . Then, after the transition to $35^{\circ} \mathrm{C}$ - $20 \% \mathrm{RH}$ for group B (point 5), the binder gets even stiffer and elastic than its initial state, which implies a certain reversibility in the mechanisms which occur during a cold period.

Generally, the binder properties vary less when the cold curing conditions happen in second. A cold season in the first 2 months of laboratory curing allows variations in modulus and phase angle, whereas in the 2 last months there is no significant change in the binder rheology.

It is important to keep in mind that here the curing is only of 4 months in a climatic chamber this is why the data changes are very low. What would be interesting would be to model or test longer curing times, where the changes would be far more significant, and see how the trends would evolve.

\section{Glass temperature, crystallised fractions and oxidation levels}

The glass transition and the crystallised fractions (Fig. 12) do not significantly change during the whole curing process. Group A glass transition starts at $-24.9{ }^{\circ} \mathrm{C}$, then reaches $-23.1{ }^{\circ} \mathrm{C}$ at the end of the first two months $\left(35{ }^{\circ} \mathrm{C}-20 \% \mathrm{HR}\right.$ ) and decreases to $-24.3{ }^{\circ} \mathrm{C}$ at the end of curing. An amplitude of less than a degree is not significant given the binder extraction procedure and the measuring process that could result in slight uncertainties. Moreover, the maximum amplitude (seen between 15 and 91 days of curing with respectively -26.2 and $22.6{ }^{\circ} \mathrm{C}$ of glass transition) is quite close to the difference between the two groups at initial state $\left(-24.9{ }^{\circ} \mathrm{C}\right.$ for A and $-27.3{ }^{\circ} \mathrm{C}$ for $\mathrm{B}$ ), even though they should be considered similar as their composition and mixing protocol are identical. Concerning the glass transition evolution of group B, it starts at $-27.3{ }^{\circ} \mathrm{C}$ (initial state), reaches $27.8{ }^{\circ} \mathrm{C}$ after 59 days of curing and ends at $-27.4{ }^{\circ} \mathrm{C}$, which is also not considered significant. The mean maximum amplitude, reached between 29 and 59 days of curing is about $2.6{ }^{\circ} \mathrm{C}$, which is also close to the difference between the two groups at initial state. Thus this is considered not significant. The evolutions of both groups are then considered as stable.

Concerning the crystallised fractions, their content stays around $3 \%$ all along the curing process for the two groups. This shows that these fractions do not vary during the four months of curing and that the binders have still not aged significantly. Indeed, literature shows that these fractions increase with bitumen ageing [15]. 

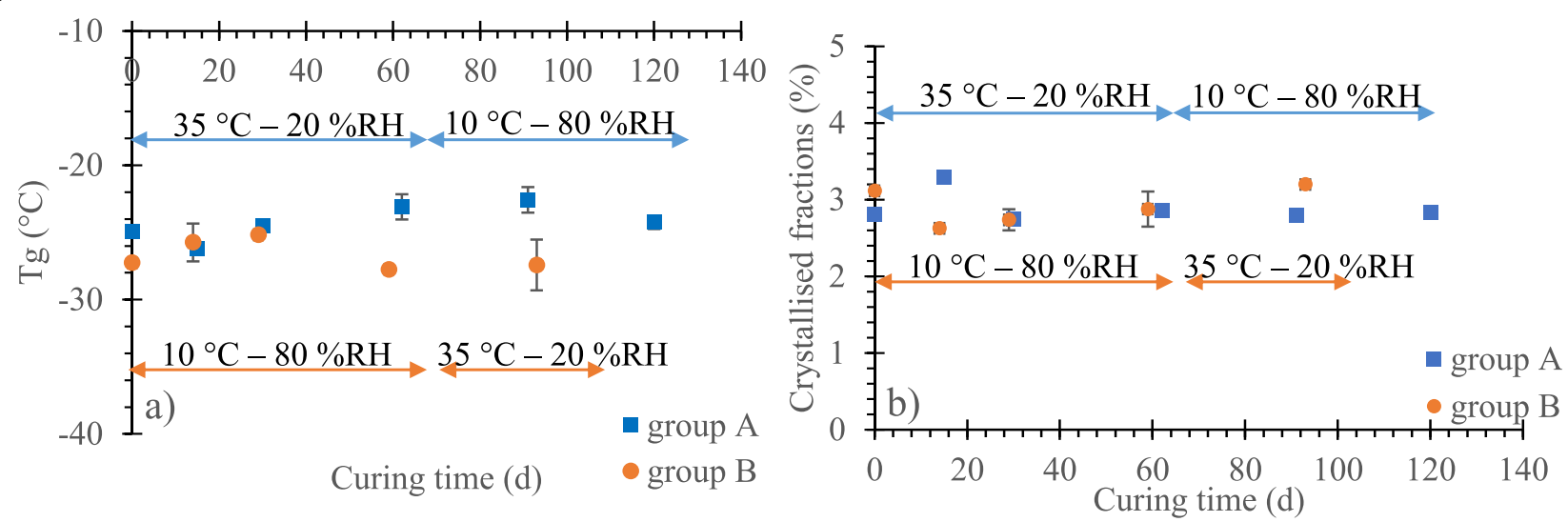

Fig. 12 (a) Glass transition, (b) Crystallised fractions versus time of the extracted binders samples. The errors bars represent the standard deviation between the two DSC results.

Infra-red oxidation levels were measured on the extracted binders of the samples from groups A and B. Figure 13 shows the carbonyl (Fig. 13-a) and sulfoxide (Fig. 13-b) oxidation indexes of these specimens at different curing times.

The initial and final oxidation levels of both groups $\mathrm{A}$ and $\mathrm{B}$ are equivalent. Moreover the kinetics of oxidation for both groups at warm period are similar as well as the ones during cold period. During warm period $\left(35^{\circ} \mathrm{C}-\right.$ $20 \% \mathrm{RH}$, first two months of group $\mathrm{A}$ and last two months of group B), the carbonyl and sulfoxide oxidation indexes significantly increase with time. During cold period $\left(10{ }^{\circ} \mathrm{C}-80 \% \mathrm{RH}\right.$, last two months of group $\mathrm{A}$ and first two months of group B) they tend to be constant which shows that there is no oxidation mechanism during a cold weather. These results show the effect of a temperature of $35{ }^{\circ} \mathrm{C}$, that accelerates oxidation.

The increase of stiffness and oxidation during curing, especially during $35{ }^{\circ} \mathrm{C}-20 \% \mathrm{RH}$ shows an oxidation of the binder. Colder conditions $\left(10{ }^{\circ} \mathrm{C}-80 \% \mathrm{RH}\right)$ seem to slow down this evolution.

\section{Discussion: Comparison between the mix mechanical behaviour and the physicochemical evolution of the extracted binder}

The $\frac{\text { finalmodulus }}{\text { initialmodulus }}$ coefficients are presented in Tables 1 and 2. These coefficients can help to understand at what amount the stiffness increased : if the coefficient is close to 1 , then the modulus did not evolve significantly ; if the coefficient is lower than 0 , the modulus decreased with time ; finally if the coefficient is higher than 1 then the stiffness improved.

Table 1 represents the coefficients between the final and the initial shear modulus and Table 2 the same coefficients on the oedometric modulus, for each group and each curing parameters, tested at $15^{\circ} \mathrm{C}$ and $10 \mathrm{~Hz}$. The $15{ }^{\circ} \mathrm{C}$ data for the extracted binder were extrapolated from the curves of $\left|G^{*}\right|$ versus test temperature to allow an easy comparison between the mix and the binder data.

First of all, the binder coefficients for each curing parameters (Table 1) are quite close: at $35{ }^{\circ} \mathrm{C}$ and $20 \% \mathrm{RH}$ group A coefficient (first curing parameters) reach around 1.5 and group B coefficient (second curing parameters) around 1.9 which can be judged as similar. This shows a stiffening of the binder during the warm curing conditions. For the $10{ }^{\circ} \mathrm{C}$ and $80 \% \mathrm{RH}$ conditions (second curing parameters for group A and first one for group B), the reactions of the groups are different. The samples from group A stagnate as their coefficient is close to 1 , while the ones from group B lose stiffness (coefficient under 1). These results are consistent with the ones discussed in the Black curves part (Figs. 10 and 11).

However, the results concerning the asphalt mix (Table 2) are mildly different as the total (« Total curing process $»$ ) and the $10{ }^{\circ} \mathrm{C}-80 \% \mathrm{RH}$ coefficient of group $\mathrm{B}$ are higher than the data from group A (explanation given below). More precisely, during the first curing parameters $\left(10{ }^{\circ} \mathrm{C}-80 \% \mathrm{RH}\right)$ the stiffness of group $\mathrm{B}$ increases as much as the stiffness of group A (around 2 for both groups) whereas throughout the second curing parameters, the coefficients of group B are higher than the one of group A. This shows that different phenomena are at stake depending on the curing parameters: when the first curing parameters simulate a cold season $\left(10{ }^{\circ} \mathrm{C}-80 \% \mathrm{RH}\right)$, not every curing physicochemical processes are triggered, which results in a continuation of stiffening after transition to the warm curing parameters $\left(35{ }^{\circ} \mathrm{C}-20 \% \mathrm{RH}\right)$. On the contrary when the first curing parameters simulate a warm season, the majority 

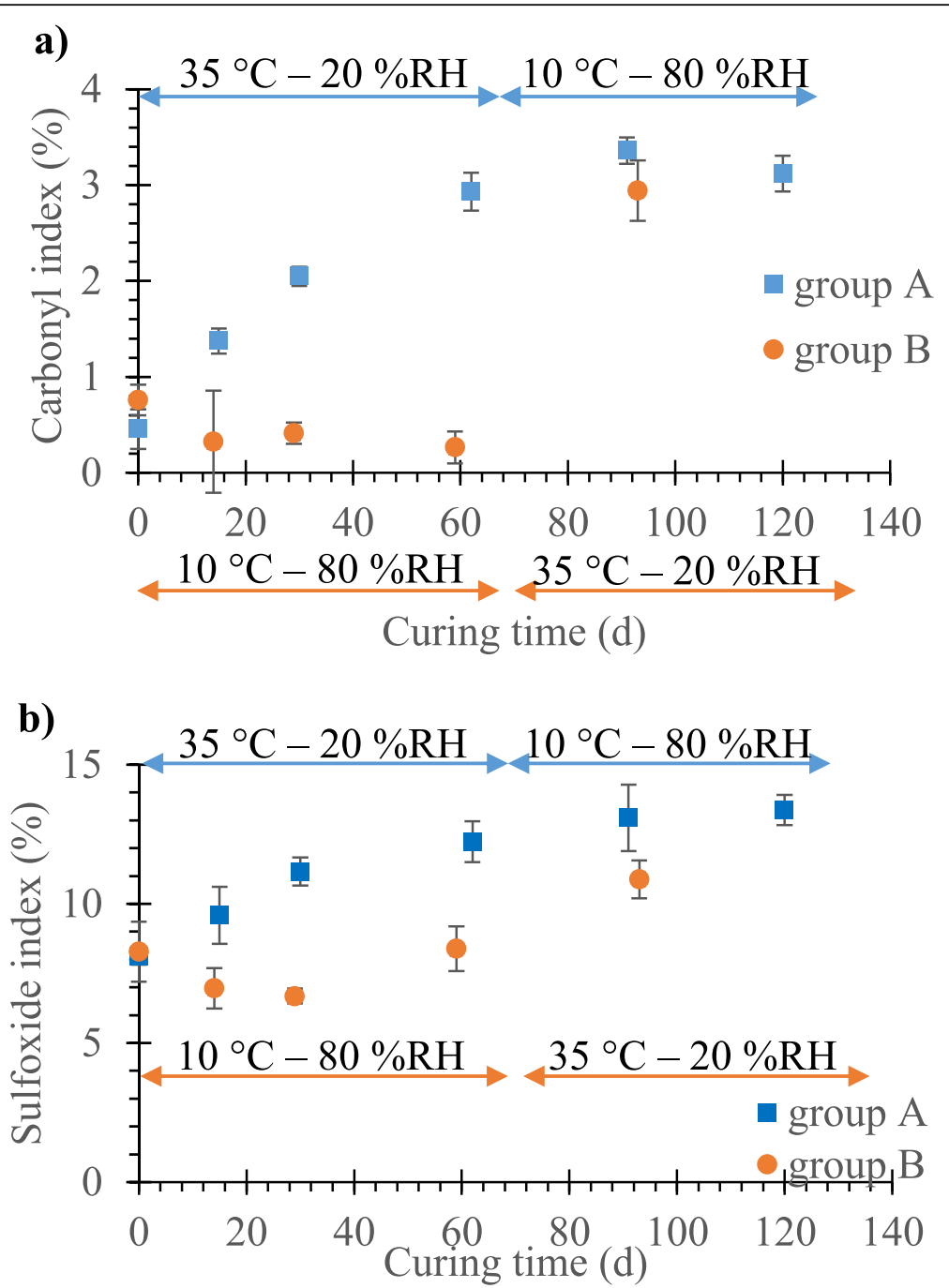

Fig. 13 Carbonyl (a) and Sulfoxide (b) oxidations indexes of the binders extracted at different curing times. The error bars represent the standard deviation of the five tests for each sample

of the curing processes are induced, that is why the stiffening coefficients of the cold season as second curing parameters are close to 1 .

Overall, the mix modulus increases faster on the four months of curing than the modulus of the binder. Furthermore, the stiffness of the binder decreases at some point, but the stiffness of the mix does not. This shows that only the binder behaviour is not enough to explain the mix evolution.

The coefficients from group A for the shear modulus (binder) and the oedometric modulus (mix) are consistent: increases of the moduli during $35{ }^{\circ} \mathrm{C}-20 \% \mathrm{RH}$ conditions and stagnation during $10{ }^{\circ} \mathrm{C}-80 \% \mathrm{RH}$ conditions. However for group B, a cold simulated season $\left(10{ }^{\circ} \mathrm{C}-80 \% \mathrm{RH}\right)$ at the beginning of curing helps the separation of some phenomena. During these conditions the binder stiffness declines (coefficient of 0.6).
The stiffening of the mix at the same time (coefficient of 2) would then be attributable to other phenomena taking place in the material. A hypothesis could deal with the bitumen-aggregate contacts quality under the influence of water.

Then, during the $35{ }^{\circ} \mathrm{C}-20 \% \mathrm{RH}$ conditions, the binder modulus (coefficient of 1.9) increases more than the mix modulus (coefficient of 1.4). This indicates once more that the evolution of the mix modulus is not entirely explained by the evolution of the binder modulus. Once again, other mechanisms are at stake.

Concerning this part, it is important to keep in mind that these coefficients may also slightly differ with the curing time chosen for the calculations. For instance the initial state (curing time $=0$ ) of the mixes are not known as the oedometer tests have begun at 3 days of curing, this may explain the proximity in coefficients between 
Table 1 Final/initial state coefficients of the extracted binder, calculated for $15^{\circ} \mathrm{C}$, and $10 \mathrm{~Hz}$

\begin{tabular}{lcc}
\hline$\left|\mathbf{G}^{*}\right|$ & Group A & Group B \\
\hline Total curing process & 1.41 & 1.16 \\
First curing parameters & 1.48 & 0.62 \\
Second curing parameters & 0.95 & 1.87
\end{tabular}

The first curing parameters for group A corresponds to $35^{\circ} \mathrm{C}-20 \% \mathrm{RH}$ and for $\mathrm{B} 10{ }^{\circ} \mathrm{C}-80 \% \mathrm{RH}$. The second one corresponds to $10{ }^{\circ} \mathrm{C}-80 \% \mathrm{RH}$ for group $\mathrm{A}$ and $35^{\circ} \mathrm{C}-20 \% \mathrm{RH}$ for group $\mathrm{B}$.

both groups for the first curing parameters; if the initial time was 0 , the coefficients of $\mathrm{A}$ would be higher than for $\mathrm{B}$, as the curing at the beginning of group $\mathrm{A}$ is faster than group B (Fig. 5) and the coefficient of "total curing process" should be close as the final states of both groups are similar (Fig. 5). Moreover there is no oedometer data between 49 and 71 days for group A so its coefficients may be fairly underestimated.

\section{Conclusions}

This paper has the purpose of bringing some new data concerning emulsion cold mix asphalts, giving leads and distinguishing the main phenomena influencing curing, and showing that it is often interesting to compare different scales of the studied material to understand its behaviour as much as possible.

The main results are:

(1) The thickness of the samples varies with the water content which can influence the stiffness,

(2) Regardless of the simulated season sequence inside the climatic chamber, based on isothermal curing processes at 35 or $10{ }^{\circ} \mathrm{C}$, the final states of the samples are similar for both groups,

(3) Warm and dry temperature-moisture parameters $\left(35^{\circ} \mathrm{C}\right.$ and $20 \% \mathrm{RH}$ ) increase the stiffness of the material and its binder ageing,

(4) Cold temperature and high moisture parameters result most of the time in a stagnation of the stiffness moduli (mix and binder) and oxidation,

(5) The Black representation is an efficient way of comparing different curing parameters, in our case $35{ }^{\circ} \mathrm{C}-20 \% \mathrm{RH}$ and $10{ }^{\circ} \mathrm{C}-80 \% \mathrm{RH}$,

Table 2 Final/initial state coefficients of the emulsion cold mix asphalt $\left(15^{\circ} \mathrm{C}, 10 \mathrm{~Hz}\right.$ and $\left.9.5 \mathrm{kN}\right)$

\begin{tabular}{lcc}
\hline$\left|E^{*}\right|$ & Group A & Group B \\
\hline Total curing process & 1.96 & 2.88 \\
First curing parameters & 1.80 & 2.02 \\
Second curing parameters & 1.09 & 1.43 \\
\hline
\end{tabular}

The first curing parameters for group A corresponds to $35^{\circ} \mathrm{C}-20 \% \mathrm{RH}$ and for $\mathrm{B} 10{ }^{\circ} \mathrm{C}-80 \% \mathrm{RH}$. The second one corresponds to $10{ }^{\circ} \mathrm{C}-80 \% \mathrm{RH}$ for group $\mathrm{A}$ and $35^{\circ} \mathrm{C}-20 \% \mathrm{RH}$ for group $\mathrm{B}$.
(6) The binder evolution does not entirely explain the mix evolution. Other physicochemical processes are to be taken into account to completely understand this type of materials, such as the influence of water.

These materials appear to be an attractive way towards a more reasoned use of bitumen as less bitumen is required to implement them. Contrary to hot mix asphalts, their behaviour progresses with time and more research could be done to improve their optimal performances.

\section{Acknowledgements}

The authors acknowledge Jean-Luc Geffard for his considerable contribution concerning the oedometer tests.

\section{Authors' contributions}

AT took part in the acquisition and analysis of the oedometric data, performed and analysed all of the other tests and was a major contributor in writing the manuscript. VG and EC directed the study and helped on the interpretation of the extracted binder data. J-MP took a priceless part in the oedometer tests analysis and interpretation. FD and CL substantively revised this paper. All authors read and approved the final manuscript.

Funding

Not applicable.

Availability of data and materials

The dataset analysed during the current study are available from the corresponding author on reasonable request.

\section{Declarations}

Competing interests

The authors declare that they have no competing interests.

\section{Author details}

${ }^{1}$ Université Gustave Eiffel/IFSTTAR (French institute of science and technology for transport, development and network), Nantes, France. ${ }^{2}$ Routes de France, Paris, France.

Received: 30 November 2020 Accepted: 26 May 2021

Published online: 12 June 2021

\section{References}

1. T.A. Doyle, C. McNally, A. Gibney, A. Tabaković, Developing maturity methods for the assessment of cold-mix bituminous materials. Construction. Building. Mater. 38, 524-529 (2013)

2. C.K. Kumar, D.S.N.V.A. Kumar, M.A. Reddy, K.S. Reddy, Investigation of coldin-place recycled mixes in India. Int .J. Pavement Eng. 9, 265-274 (2008)

3. J.-P. Serfass, J.-E. Poirier, J.-P. Henrat, X. Carbonneau, Influence of curing on cold mix mechanical performance. Mater. Structures. 37, 365-368 (2004)

4. L.D. Poulikakos, B. Hofko, L. Porot, X. Lu, H. Fischer, N. Kringos, Impact of temperature on short- and long-term aging of asphalt binders. RILEM Technical Letters. 1, 6-9 (2016)

5. J. Lamontagne, P. Dumas, V. Mouillet, J. Kister, Comparison by Fourier transform infrared (FTIR) spectroscopy of different ageing techniques: application to road bitumens. Fuel. 80, 483-488 (2001)

6. A. Béghin, L. Wendling, X. Carbonneau, C.d.L. Roche, F. Delfosse, V. Gaudefroy, L. Odie, J.-M. Piau, J.-P. Triquigneaux, Behavior and design of grave-emulsion, public-private cooperation: Curing and evolution over time of the mix properties and binder characteristics. European roads review (RGRA). 19, (2011)

7. J.-P. Triquigneaux, L. Wendling, L. Odie, D. Claudel, V. Gaudefroy, Behavior and study of emulsified asphalt mixes, public-private cooperation: Duriez test : voids content, mechanical performance, sensitivity to water and characterization of extracted binders. European roads review (RGRA). 19, (2011) 
8. F. Delfosse, A. Béghin, A. Belkahia, V. Gaudefroy, C. Gueit, L. Odie, Comportement et étude des graves-émulsion, corrélation entre le comportement en place sur la RD 26 et le laboratoire. European roads review (RGRA, in French). 954, (2018)

9. M. Lambert, J.-M. Piau, V. Gaudefroy, A. Millien, F. Dubois, C. Petit, F. Chaignon, Modeling of cold mix asphalt evolutive behaviour based on nonlinear viscoelastic spectral decomposition. Construction Building Materials. 173, 403-410 (2018)

10. A. Graziani, C. lafelice, S. Raschia, D. Perraton, A. Carter, A procedure for characterizing the curing process of cold recycled bitumen emulsion mixtures. Construction Building Materials. 173, 754-762 (2018). https://doi. org/10.1016/j.conbuildmat.2018.04.091

11. Z. Chen, J. Yi, H. Zhao, H. Luan, M. Xu, L. Zhang, D. Feng, Strength development and deterioration mechanisms of foamed asphalt cold recycled mixture based on MD simulation. Construction Building Materials. 269, 121324 (2021). https://doi.org/10.1016/j.conbuildmat.2020.121324

12. J.-P. Serfass, X. Carbonneau, F. Delfosse, J.-P. Triquigneaux, Grave-emulsion assessment and behavior. RGRA. 889, (2010)

13. G. Flores, J. Gallego, L. Miranda, J.R. Marcobal, Cold asphalt mix with emulsion and $100 \%$ rap: Compaction energy and influence of emulsion and cement content. Construction and Building Materials. 250, 118804 (2020). https://doi.org/10.1016/j.conbuildmat.2020.118804

14. G. Gauthier, D. Bodin, E. Chailleux, T. Gallet, Non Linearity in Bituminous Materials during Cyclic Tests. Road Materials and Pavement Design. 11, 379410 (2010). https://doi.org/10.1080/14680629.2010.9690339

15. M. Le Guern, E. Chailleux, F. Farcas, S. Dreessen, I. Mabille, Physico-chemical analysis of five hard bitumens: Identification of chemical species and molecular organization before and after artificial aging. Fuel. 89, 3330-3339 (2010). doi:https://doi.org/10.1016/j.fuel.2010.04.035

\section{Publisher's Note}

Springer Nature remains neutral with regard to jurisdictional claims in published maps and institutional affiliations.

\section{Submit your manuscript to a SpringerOpen ${ }^{\circ}$ journal and benefit from:}

- Convenient online submission

- Rigorous peer review

- Open access: articles freely available online

High visibility within the field

- Retaining the copyright to your article

Submit your next manuscript at $\boldsymbol{\nabla}$ springeropen.com 